\title{
Sintesis dan Karakterisasi Sifat Optik Nanopartikel Silika yang Dilapisi Nanopartikel Emas
}

\author{
Ebriyen Zeni $^{1{ }^{*}}$, Muldarisnur ${ }^{1}$, Syukri $^{2}$ \\ ${ }^{1}$ Laboratorium Fisika Material, Jurusan Fisika \\ ${ }^{2}$ Laboratorium Kimia Material, Jurusan Kimia \\ Fakultas Matematika dan Ilmu Pengetahuan Alam Universitas Andalas \\ Kampus Unand Limau Manis, Padang, 25163, Indonesia \\ *ebriyenzeni24@yahoo.co.id
}

\begin{abstract}
ABSTRAK
Telah dilakukan sintesis dan karakterisasi struktur dan sifat optik nanopartikel silika yang dilapisi nanopartikel emas. Sintesis dilakukan pada suhu $95^{\circ} \mathrm{C}$ dengan variasi rasio mol APTES terhadap gugus silanol pada nanopartikel silika sebesar 1,0 dan 1,4 serta Au 0,1 dan 0,2 ml. Karakterisasi dilakukan menggunakan FTIR, SEM-EDS, dan Spektrofotometer UV-Vis. Spektrum FTIR menunjukkan adanya ikatan antara APTES dengan silika pada daerah serapan sekitar $1500 \mathrm{~cm}^{-1}$ dan keberadaan nanopartikel emas ditunjukkan dari hasil SEM-EDS. Karakterisasi SEM menunjukkan nanopartikel emas menempel pada permukaan silika. Respon magnetik sampel ditunjukkan dari hasil spektrofotometer UV-Vis dengan dua puncak yaitu resonansi dipol dan resonansi kuadrupol.

Kata kunci: APTES, nanopartikel emas, nanopartikel silika, respon magnetik, sifat optik
\end{abstract}

ABSTRACT

Syntesis and optical as well as structural characterization of dielectric nanoparticles coated with gold nanoparticles have been performed. The synthesis was carried out at $95{ }^{\circ} \mathrm{C}$ by varying APTES to the silanol gruoup on a silica nanoparticles of 1,0 dan 1,4 and Au concentration that were 0.1 and 0,2 $\mathrm{ml}$. Characterization was performed using FTIR, SEM-EDS, and UV-Vis Spectrophotometer. The FTIR spectra indicate that APTES and silica are chemically bound as seen from absorption in the region of $1500 \mathrm{~cm}^{-1}$ and the presence of gold nanoparticles on the surface of silica nanoparticles is shown from SEM-EDS results. The magnetic response of the samples is vesible from the UV-Vis spectrophotometer by the appearance of the two peaks that corresspond to dipole and quadrupole resonances.

Keywords: APTES, silica nanoparticles, gold nanoparticles, response magnetic, optical properties

\section{PENDAHULUAN}

Sains dan rekayasa material berukuran nanometer yang dikenal dengan nanosains dan nanoteknologi berkembang sangat pesat dalam dua dekade terakhir (Abdullah, 2009). Perkembangan ini didorong oleh unggulnya sejumlah sifat fisika dan kimia dari material berukuran nanometer dibanding material berukuran besar (bulk). Perbedaan sifat ini disebabkan oleh dominannya efek kuantum dan semakin besarnya fraksi atom yang berada dipermukaan material. Hal ini memungkinkan kontrol atas sifat material berukuran nano sesuai kebutuhan dengan memvariasikan ukuran dan bentuk geometrinya.

Salah satu topik yang banyak diteliti saat ini adalah kemungkinan membuat bahan dengan indeks bias negatif yang tidak ditemukan di alam. Bahan dengan indeks bias negatif dapat menghasilkan lensa dengan resolusi jauh lebih tinggi yaitu hingga puluhan nanometer. Indeks bias negatif hanya ditunjukkan oleh bahan dengan permitivitas dan permeabilitas keduanya bernilai negatif pada rentang panjang gelombang tertentu. Permitivitas negatif dimiliki oleh nanopartikel logam mulia pada frekuensi di bawah frekuensi resonansi plasmonik yaitu di daerah cahaya tampak dan infra merah. Sayangnya, permeabilitas negatif sulit diperoleh pada rentang frekuensi ini karena orientasi momen magnetik spin dan orbital menjadi acak pada frekuensi tinggi.

Sifat magnetik dalam rentang cahaya tampak dan infra merah hanya dapat ditunjukkan oleh struktur buatan (metamaterial) dari logam mulia seperti emas, perak dan perunggu. Beberapa struktur buatan menunjukkan respon magnetik pada rentang tersebut seperti pasangan batangan nano (nano-rods dan nano-bars) yang disusun sejajar (Podolskiy dkk., 2002 dan Shalaev dkk., 2005), kluster nanopartikel berbentuk lingkaran (Alu dan Engheta, 2008) dan kluster nanopartikel berbentuk kubus (Alu dan Engheta, 2009) yang menghasilkan respon magnetik isotropik, kluster amorf (Dintinger dkk., 2012) menghasilkan respon magnetik 
anisotropik, serta kluster nanopartikel logam dengan inti dari bahan dielektrik (Simovski dan Tretyakov, 2009). Struktur-struktur buatan ini harus difabrikasi menggunakan teknik litografi, teknik litografi ini menunjukkaan respon magnetik yang kuat tapi memiliki banyak keterbatasan misalnya sulit mencapai bahan dengan ukuran nanometer (Mühlig, 2011).

Di antara logam mulia yang ada, perak menunjukkan resonansi yang paling kuat. Walaupun memiliki resonansi plasmonik paling kuat, perak jarang digunakan untuk menghasilkan bahan berindeks bias negatif karena mudah teroksidasi. Emas sering dipilih karena bersifat biokompatibel dan inert sehingga tidak mengalami oksidasi dan korosi. Salah satu contoh penggunaan nanopartikel emas dibidang kesehatan adalah sebagai biosensor dan untuk terapi kanker (Prashant dan El-sayed, 2007).

Penelitian tentang nanopartikel dengan respon magnetik isotropik sudah dilakukan oleh Mizhlig dkk. (2011) dengan menumbuhkan nanopartikel emas dari prekursor asam chloroauric $\left(\mathrm{HAuCl}_{4}\right)$ dipermukaan silika. Konsentrasi nanopartikel logam yang ditumbuhkan pada permukaan nanopartikel dielektrik sayangnya masih terlalu rendah. Rendahnya konsentrasi nanopartikel logam berakibat pada lemahnya respon magnetik yang dihasilkan.

Untuk mendapatkan respon magnetik isotropik dari hasil karakterisasi UV-Vis, pada penelitian ini telah disintesis nanopartikel yang terdiri dari nanopartikel silika sebagai inti dan ditutupi oleh klaster nanopartikel logam mulia yang diharapkan tersebar merata dipermukaan silika. Nanopartikel emas tidak ditumbuhkan sendiri, melainkan diikatkan secara kimiawi ke permukaan silika. Kebergantungan respon magnetik terhadap konsentrasi nanopartikel emas pada permukaan silika akan diteliti dengan memvariasikan konsentrasi senyawa fungsional yang digunakan.

\section{METODE}

Pembuatan sampel dilakukan di Laboratorium Fisika Material Jurusan Fisika Universitas Andalas, karakterisasi FTIR dan UV-Vis di Laboratorium Kimia Jurusan Kimia Universitas Negeri Padang, dan SEM di Laboratorium Scanning Electron Microscopy Institut Teknologi Bandung. Penelitian dilakukan dari Oktober 2017 sampai Februari 2018. Peralatan yang digunakan dalam penelitian ini adalah neraca digital, magnetic stirrer, termometer, syiringe $1 \mathrm{ml}$, beaker glass, penangas, oven, dan alat uji karakterisasi yaitu FTIR, UV-Vis, dan SEM. Bahan yang digunakan adalah nanopartikel silika, nanopartikel emas, etanol dan APTES.

Langkah-langkah pembuatan sampel nanopartikel silika yang dilapisi nanopartikel emas adalah sebagai berikut:

1. Silika diaktivasi dengan cara dipanaskan menggunakan penangas pada suhu $200{ }^{\circ} \mathrm{C}$.

2. Kemudian silika teraktivasi difungsionalisasi dengan APTES (Aminoprophyl Trietoxysilane). Variasi perbandingan APTES terhadap gugus silanol dari silika (rasio mol) yang digunakan adalah 1,0 dan 1,4 .

3. Silika yang telah difungsionalisasi APTES ditambahkan ke dalam larutan etanol kemudian dipanaskan dalam suhu $95^{\circ} \mathrm{C}$ sambil di-stirrer.

4. Campuran tersebut dikeringkan menggunakan oven dan selanjutnya dilakukan pengujian FTIR untuk melihat gugus fungsi dari silika dan APTES.

5. Kondisi optimal darihasil FTIR akan ditambahkan nanopartikel emas secara perlahan dengan variasi 0,1dan $0,2 \mathrm{ml}$ dan di-stirrer selama 1 jam.

6. Padatan nanopartikel disimpan dalam botol plastik untuk kemudian dikarakterisasi.

\section{HASIL DAN DISKUSI}

\subsection{Gugus fungsi yang terkandung dalam silika termodifikasi APTES}

Karakterisasi dengan FTIR dalam penelitian ini bertujuan untuk mengetahui berhasil atau tidaknya fungsionalisasi nanopartikel silika dengan APTES. Telah dilakukan karakterisasi FTIR untuk sampel silika yang termodifikasi APTES dengan variasi rasio mol APTES 1,0 dan 1,4 . 


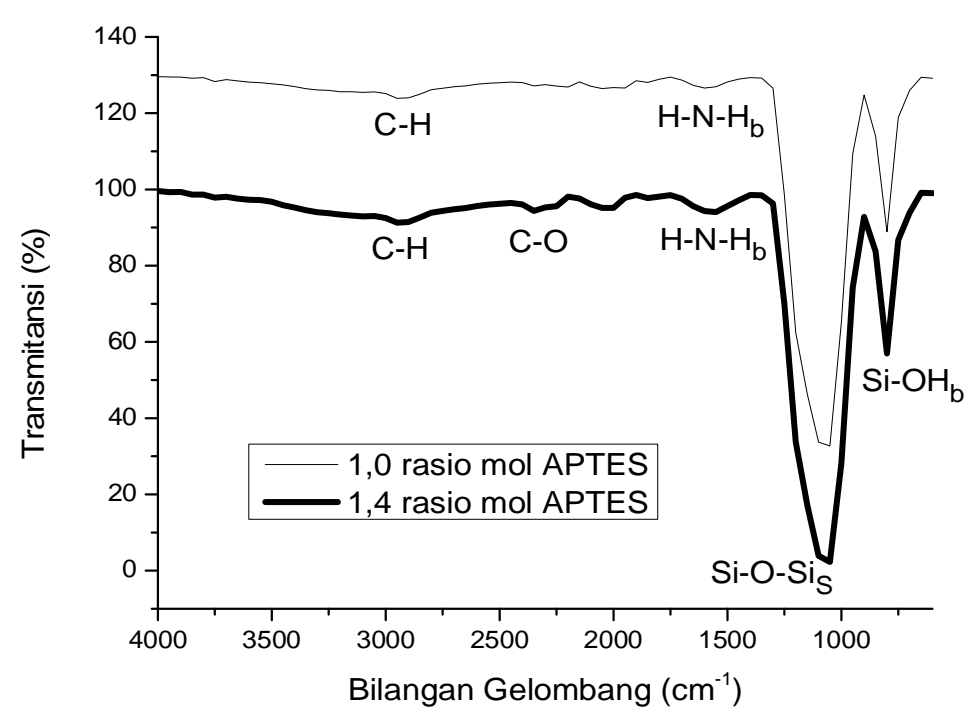

Gambar 1 Spektrum FTIR dari silika termodifikasi APTES. Kurva 1,0 rasio mol APTES digeser sebesar $30 \%$

Gambar 1 memperlihatkan kemunculan pita serapan yang kuat dan spesifik pada daerah bilangan gelombang sekitar $1000 \mathrm{~cm}^{-1}$ yang merupakan vibrasi khas backbone Si-O-Si. Bilangan gelombang sekitar $800 \mathrm{~cm}^{-1}$ pita serapan Si-OH bending, proses modifikasi menyebabkan sedikit pengurangan intensitas vibrasi $\mathrm{Si}-\mathrm{OH}$ karena sebagian telah bereaksi dengan APTES. Pita serapan lain yang muncul setelah modifikasi adalah $\mathrm{H}-\mathrm{N}-\mathrm{H}$ bending pada daerah bilangan gelombang sekitar $1500 \mathrm{~cm}^{-1}$ dan vibrasi ulur C-H padas ekitar $2900 \mathrm{~cm}^{-1}$. Hal ini mengindikasikan adanya modifier (APTES) pada permukaan silika sehingga dapat dikatakan bahwa proses fungsionalisasi silika telah berhasil dilakukan.

Terdapat perbedaan pita serapan dari kedua sampel yaitu pada bilangan gelombang sekitar $2300 \mathrm{~cm}^{-1}$, untuk sampel 1,4 rasio mol APTES muncul pita serapan C-O yang menandakan keberadaan $\mathrm{CO}_{2}$ terserap, hal itu tentu tidak diinginkan karena dapat merusak permukaan silika yang akan mengikat emas. Maka sampel dengan 0,44 ml APTES dipilih untuk sintesis selanjutnya karena tidak mengandung pengotor $\mathrm{CO}_{2}$.

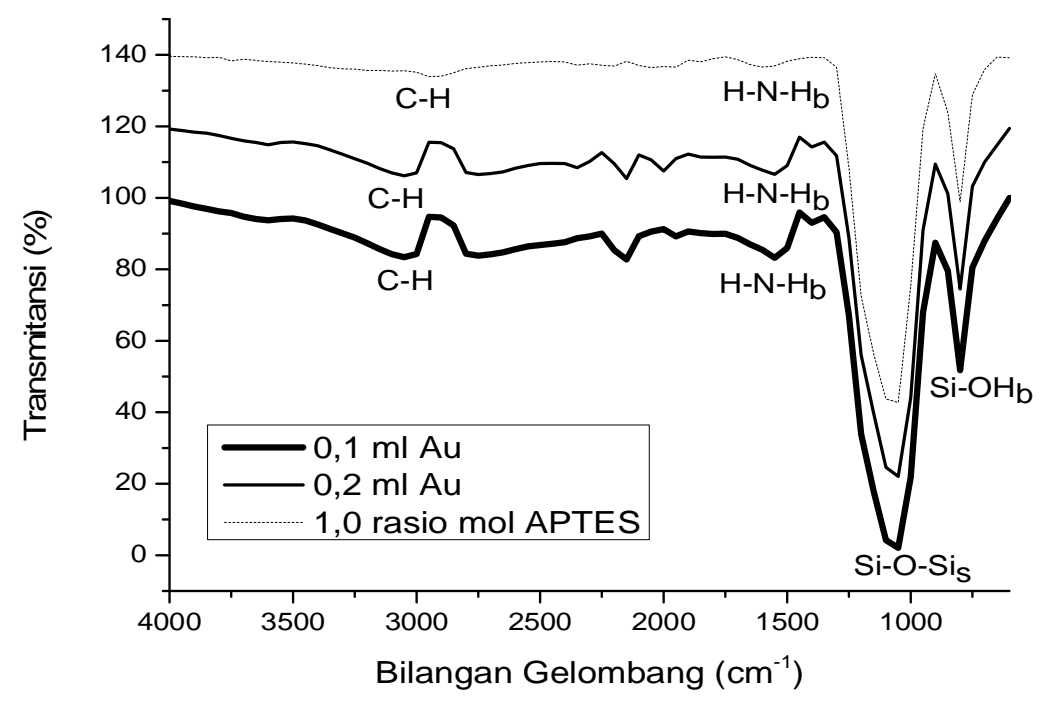

Gambar 2 Spektrum FTIR dari silika termodifikasi APTES dan dilapisi emas. Kurva 0,2 ml Au digeser sebesar 20\% dan1,0 rasio mol APTES sebesar $40 \%$ 
Gambar 2 merupakan sampel yang mengandung emas yang dianalisis pada kondisi optimal variasi APTES. Pada Gambar 2 ini terdapat perubahan pada pola pita serapan $\mathrm{H}-\mathrm{N}-\mathrm{H}$ bending yang menandakan $\mathrm{H}-\mathrm{N}-\mathrm{H}$ mengikat nanopartikel emas sehingga frekuensi vibrasinya mengecil dan bergeser kearah panjang gelombang yang lebih tinggi. Perubahan pada pola pita serapan ini mengindikasikan adanya nanopartikel emas yang menempel pada permukaan silika.

\subsection{Hasil analisis dengan SEM}

Karakterisasi SEM dilakukan untuk mengetahui morfologi permukaan pada sampel nanopartikel silika yang dilapisi nanopartikel emas. Hasil karakterisasi ditampilkan pada Gambar 3 yang menunjukkan bahwa ukuran partikel sampel komposit tersebut cukup merata berupa agregat-agregat dan dapat pula diamati adanya pori-pori eksternal yang terdapat pada beberapa area permukaan. Hasil SEM menunjukkan adanya angka-angka yang mucul di permukaan sampel yaitu diantara $0,02-0,03 \mu \mathrm{m}$. Ukuran partikel yang terukur dari hasil SEM ini sebanding dengan ukuran partikel silika. Dengan munculnya ukuran ini menunjukkan bahwa nanopartikel silika terdapat pada sampel, tetapi ukuran dari nanopartikel emasnya tidak muncul disebabkan karena fokus SEM yang masih kurang memadai, tetapi nanopartikel emas dapat diindikasikan seperti lapisan luar yang berwarna gelap dibandingkan warna dari nanopartikel silika yang abu-abu.

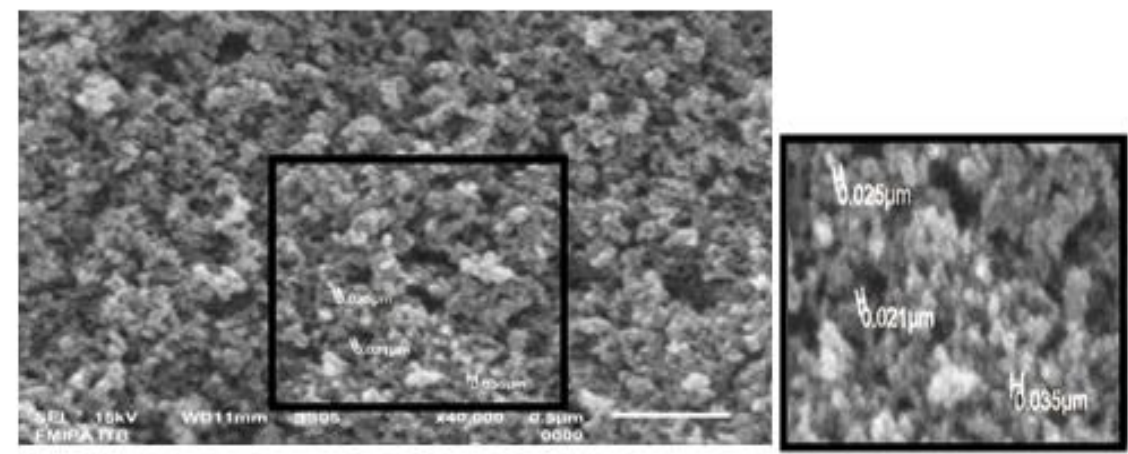

Gambar 3 Gambar SEM dengan sampel 1,0 rasio mol APTES + Au 0,1 ml

\subsection{Hasil analisis dengan EDS}

Komposisi unsur kimia yang terdapat pada permukaan sampel $\mathrm{SiO}_{2}$-APTES-Au yang diuji dapat diketahui dengan EDS. Spektrum EDS ditunjukkan pada Gambar 4, mengindikasikan bahwa sampel mengandung unsur $\mathrm{Si}$ dan $\mathrm{O}$ yang berasal dari silika $\left(\mathrm{SiO}_{2}\right), \mathrm{C}$ berasal dari APTES $\left(\mathrm{C}_{9} \mathrm{H}_{23} \mathrm{NO}_{3} \mathrm{Si}\right)$ dan Au seperti yang telah diprediksi sebelumnya. Hal ini juga menjadi petunjuk keberhasilan modifikasi $\mathrm{SiO}_{2}$ dengan APTES dan kemampuannya memuat Au. Puncak Au yang muncul pada Gambar 4 lebih rendah dibandingkan puncak silika, hal ini disebabkan oleh ukuran dan konsentrasi nanopartikel emas yang jauh lebih besar dari nanopartikel silika.

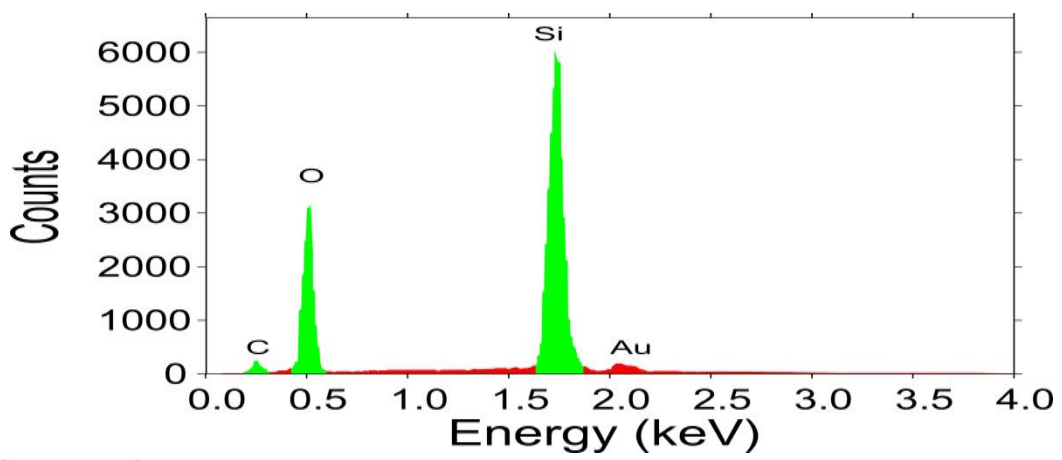

Gambar 4 Gambar EDS dengan sampel 1,0 rasio mol APTES + Au 0,1 ml 


\subsection{Hasil analisis dengan spektrofotometer UV-Vis}

Pengukuran dengan spektrofotometer UV-Vis dilakukan agar dapat diketahui absorbansi maksimum serta panjang gelombang maksimum dari sintesis nanopartikel silika yang dilapisi nanopartikel emas. Grafik dari hasil UV-Vis dapat dilihat pada Gambar 5.

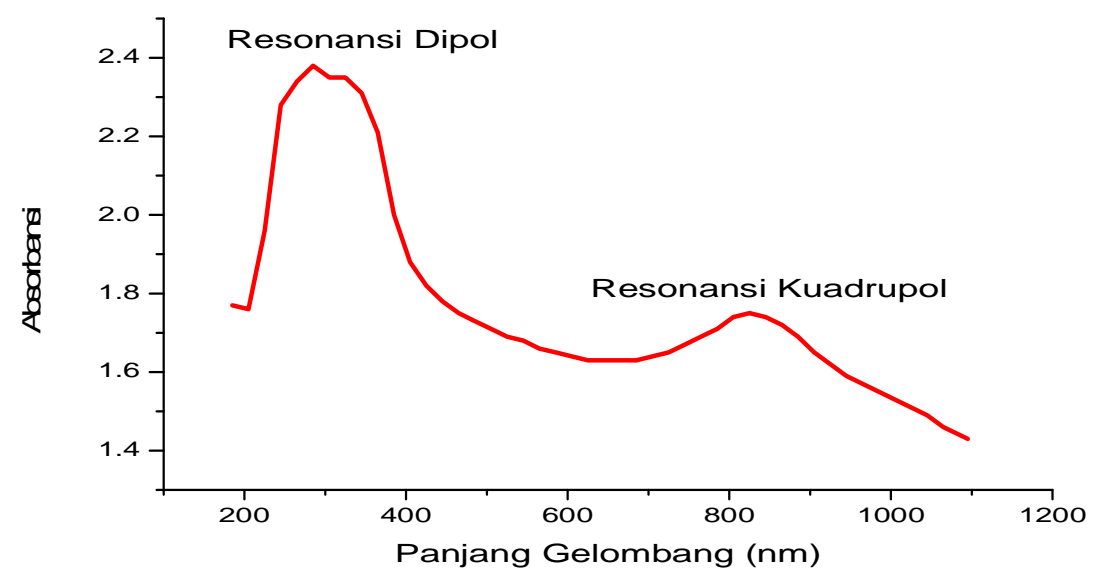

Gambar 5 Spektrum UV-Vis silika + 1,0 rasio molAPTES + Au 0,1 ml

Berdasarkan hasil spektrum UV-Vis pada Gambar 5 dapat dilihat adanya peningkatan serapan pada daerah sinar tampak yaitu pada panjang gelombang $200-400 \mathrm{~nm}$, dimana puncak ini dihasilkan oleh resonansi dipol. Spektrum UV-Vis memperlihatkan adanya puncak kedua yang terlihat merupakan serapan dari nanopartikel emas yang memiliki warna merah, puncak ini dihasilkan oleh resonansi kuadrupol. Resonansi kuadrupol muncul secara alami ketika interaksi nanopartikel terjadi antara inti nanopartikel (silika) dan nanopartikel sekitarnya (emas) (Jiang dkk., 2014). Resonansi kuadrupol ini yang dapat menghasilkan respon magnetik yang isotropik karena terbentuknya arus yang melingkar.

\section{KESIMPULAN}

Berdasarkan hasil penelitian ini dapat diketahui bahwa indikasi menempelnnya nanopartikel emas di permukaan silika ditandai dengan adanya perubahan pada pola pita serapan $\mathrm{H}-\mathrm{N}-\mathrm{H}$ bending disekitar $1500 \mathrm{~cm}^{-1}$, dibuktikan dengan munculnya unsur Au dari hasil EDS, serta munculnya puncak resonansi dipol dan kuadrupol pada spektrum UV-Vis. Puncak pada spektrum UV-Vis menghasilkan respon magnetik yang bersifat isotropik pada rentang cahaya tampak. Respon magnetik ini diindikasikan dengan terjadinya pergeseran puncak kuadrupol yang disebabkan oleh resonansi momen magnetik dipol.

\section{DAFTAR PUSTAKA}

Abdullah, M., Pengantar Nanosains (ITB, Bandung, 2009), hal 1.

Alù, A., and Engheta, N., "Dynamical Theory of Artificial Optical Magnetism Produced by Rings of Plasmonic Nanoparticles", Phys. Rev. 78, 1-34 (2008).

Alù, A., and Engheta, N., "The Quest for Magnetic Plasmons at Optical Frequencie”, Opt. Exp. 17, 5723-5730 (2009).

Dintinger, J., Mühlig, S., Rockstuhl, C., and Scharf, T., "A Bottom-up Approach to Fabricate Optical Metamaterials by Self-assembled Metallic Nanoparticles", Opt. Mater. Express. 2, 269-278 (2012).

Jiang, M., Chen, H., Li. B., Li, K., Shan, C., and Shen, D., "Hybrid Quadrupolar Resonances Stimulated at Short Wavelengths Using Coupled Plasmonic Silver Nanoparticle Agregation", Journal of Materials Chemistry C. 2, 56-63 (2014).

Mizhlig, S., Cunningham, A., Scheeler, S., Pacholski, C., B zirgi, T.,Rockstuhl, C., and Lederer, F., "Self-Assembled Plasmonic Core-Shell Clusters with an Isotropic Magnetic Dipole Response in the Visible Range", ACSNANO. 5, 6586-6592 (2011). 
Podolskiy, V.A., Sarychev, A. K., and Shalaev, V. M., "Plasmon Modes in Metal Nanowires", J. Nonlinear Opt. Phys. Mater. 11, 65-74 (2002).

Prashant, K., and El-sayed. M. A., "Au nanoparticle target cancer", nanotoday. 2, 18-28 (2007)

Shalaev, V. M., Cai, W., Chettiar, U. K., Yuan, H.-K., Sarychev, A.K., Drachev, V.P., and Kildishev, A.V., Negative Index of Refraction in Optical Metamaterials”, Opt. Lett. 30, 3356-3358 (2005).

Simovski, C. R. and Tretyakov, S. A., "Model of Isotropic Resonant Magnetism in the Visible Range Based on Core-shell Clusters", Phys. Rev. B. 79, 1-9 (2009). 